\title{
Hierarchy Among Selves: An Implication for Relations With Persons Versus Groups
}

\author{
Lowell Gaertner, Constantine Sedikides, \\ Michelle Luke, and Jonathan Iuzzini
}

In this chapter, we discuss motivational-primacy research as a framework for contemplating when egoism can be transcended. Our research examines which of three fundamental forms of self-definition-the individual self (i.e., self as a unique and independent social agent), the relational self (i.e., self as an interconnected partner in an interpersonal relationship), and the collective self (i.e., self as an undifferentiated and interchangeable member of a group)-is experientially more essential; psychologically the home base; or, alternatively, motivationally primary. Stated metaphorically, we ask which self smiles brighter when enhanced and screams louder when threatened. As we discuss in this chapter, data from several studies evidence a motivational hierarchy with the individual self elevated above the other two selves, and the relational self elevated above the collective self.

In the context of that hierarchy, a quieter ego can be conceptualized as a self-system in which the motivational striving of the individual self is deemphasized and brought into balance with the strivings of the other selves. A quieter or transcended ego, for example, could appear as a lessened concern for protecting and enhancing the individuated person and a heightened concern for protecting and enhancing others through their inclusion in the relational or collective self. Central to this chapter is the implication from the hierarchy that such transcendence is more likely when social relations involve another person, who is internalized through the relational self, than when relations involve a group, which is internalized through the collective self. We begin the chapter with a review of the primacy research to justify and frame the persongroup implication and proceed with exploring the implication in the context of three diverse bodies of research.

\section{A Hierarchy Within}

Initial research compared the motivational primacy of the individual versus the collective self, with the assumption that the primary self would react more 
fervently when threatened or enhanced (L. Gaertner, Sedikides, \& Graetz, 1999). L. Gaertner et al. (1999) manipulated threat of the individual or collective self and enacted particular care to control the relative salience of each self to avoid the possibility that primacy is simply a function of contextual salience. Across experiments, they (a) assessed multiple reactions to threat (e.g., anger, mood state, strategic self-perceptions, derogation of the threat), (b) controlled various confounding variables (e.g., domain of threat, relative importance of the threat domain, delay between the onset of threat and assessment of reaction), (c) targeted a variety of ingroups serving as a collective self (e.g., ascribed groups, achieved groups, novel groups), and (d) invoked multiple methods for varying the selves' salience (e.g., simultaneously activated both selves, maximized the salience of one self and minimized the salience of the other, premeasured idiographic identification with the targeted ingroup). Providing initial evidence for the motivational primacy of the individual self, participants reacted more strongly to a threat to their individual self than their collective self.

L. Gaertner, Sedikides, Vevea, and Iuzzini (2002) then replicated and extended the finding of individual-self primacy while addressing the possibility that L. Gaertner et al.'s (1999) initial evidence was unique to the specific threats, measures, and groups used. They searched the empirical literature and conducted a random-effects meta-analysis that assessed the relative reaction of the individual versus collective self to threat and enhancement. The existing experiments used various threats or enhancements, measured an array of reactions, and targeted a variety of ingroups representing the collective self. They addressed the possibility that primacy varies with the contextual salience of a self by coding two variables: (a) whether the targeted ingroup was a novel group formed in the laboratory or a preexisting group (e.g., sorority, university affiliation, political party) and (b) strength of ingroup identification (i.e., the extent to which members identified with the group). Neither variable moderated the results. The data evidenced individual-self primacy: Participants reacted more fervently to both threat and enhancement of their individual than collective self. The self-concept is characterized by a motivational hierarchy along which the individual self has a privileged position.

\section{Wherein Lies the Relational Self?}

Absent from past research was the relational self. There are reasons to argue, however, that the relational self, forged from close interpersonal bonds, has an elevated status along the motivational hierarchy (Tice \& Baumeister, 2001). The dyad, for example, which enables internal fertilization and provides the bond that promotes infant survival (Bowlby, 1969), is phylogenetically the most ancient repeated social configuration (Caporael, 1997). Indeed, given the widespread detriments to mental and physical health that people experience when deprived of stable relationships, the need to belong (i.e., the desire "to form and maintain strong, stable, interpersonal relationships"; Baumeister \& Leary, 1995, p. 497) is considered a fundamental human motive.

We recently completed three experiments comparing the relative motivational positioning of the individual, relational, and collective selves (L. Gaert- 
ner, Sedikides, Luke, \& Iuzzini, 2007). We used different approaches to assess motivational primacy across studies. In Experiment 1, we examined reaction to threat, as earlier research had. In Experiment 2, we examined relative valuing of each self. In Experiment 3, we examined proactive capacity to affect a desired future in terms of the extent to which the selves differentially contribute to future goals (Gollwitzer \& Moskowitz, 1996). Likewise, we used different techniques for controlling the salience of the selves across studies. In Experiments 1 and 2, we made the selves simultaneously salient, whereas in Experiment 3 we differentially primed each self.

Participants in Experiment 1 read definitions of each self, recorded the most important trait they possessed that completely defined them in regard to each self (i.e., three different traits), and completed an imagination task for each self (L. Gaertner et al., 2007). Participants imagined awaking after having had a given self's most important trait surgically removed and then rated their reaction to the loss in terms of the extent to which they would be negatively impacted, remain the same person, experience a meaningless life, and experience a negative mood. All four measures evidenced an equally strong reaction to loss of the trait associated with the individual self and the relational self. Three measures evidenced stronger reaction to the imagined loss of the trait for either the individual self (impact, same person, and mood) or the relational self (impact, meaningless life, and mood) than for the collective self. Furthermore, in no instance did loss of the collective-self trait elicit a stronger response. The results, which suggested that the elevated motivational status of the individual and relational selves is not unique or limited to young adults, were consistent across a broad age range (17-57 years).

Participants in Experiment 2 read definitions of each self and completed three forced comparisons in which they distributed a fixed sum of money among the selves to indicate their relative value (L. Gaertner et al., 2007). Participants indicated how much they would (a) spend improving each self, (b) price the worth of each self, and (c) anticipate receiving in a sale of each self. Participants more strongly valued the individual self and the relational self over the collective self on all three measures, more strongly valued the individual self than the relational self on the sale measure, and equally valued the individual self and relational self on the spending and pricing measures.

Participants in Experiment 3 wrote a narrative describing themselves in terms of the individual, relational, or collective self; listed 12 goals they had for their future; and, in a counterbalanced order, rated the importance of each goal and indicated the self to which each goal corresponded (L. Gaertner et al., 2007). Participants attributed more goals to the individual self (i.e., $56 \%$ of all goals) than to the relational self or the collective self, with women attributing more goals to the relational self (i.e., 25\%) than to the collective self (i.e., 19\%) and men attributing an equal number of goals to those selves (i.e., $22 \%$ ). We subsequently examined whether the goal that received the highest importance rating for one self was more important than the most important goal of the other selves. Participants rated their most important individual-self goal as more important than their most important relational-self goal, which in turn they rated as more important than their most important collective-self goal. These patterns persisted regardless of whether participants initially described themselves in terms of their individual self, relational self, or collective self. 
Despite their different measures and methods for examining motivational primacy, the three experiments evidenced remarkably similar findings (L. Gaertner et al., 2007). These findings replicated previous research in that they illustrated the elevated motivational status of the individual self over the collective self. The findings also established the elevated status of the relational self over the collective self. Comparisons of the individual and relational selves, however, were mixed. Most measures evidenced an equivalent status of the latter selves, but when differences emerged they favored the individual self. The weight of the current empirical evidence tentatively points to the elevated status of the individual self over the relational self. Without empirical dispute, however, is the elevated motivational status of both the individual and relational selves over the collective self.

\section{An Implication for a Quieter Ego}

If ego is equated with the motivational striving of the individual self, then the motivational hierarchy, particularly the elevated status of the relational self over the collective self, offers an implication for the possibility of a quieter ego. The hierarchy implies that transcendence of egoism varies with whether social relations involve persons or groups. When the motivational strivings of the three selves are noncorrespondent, the elevated status of the relational self will better challenge or assuage the motivational striving of the individual self than will the lower status collective self. Put otherwise, the motivational striving of the individual self will be less influential when relating with a person, who is internalized in the self system through the relational self, than when relating with a group, which is internalized through the collective self. To be clear, the implication is not necessarily an absolute silencing of the individual self. The implication is a relative silencing such that the individual self will be quieter when relations involve another person than a group.

\section{Glimpsing a Quieter Ego With Persons Than With Groups}

The social science literature provides glimpses of the possibility for a quieter ego in relations with persons than with groups. The glimpses, some of which are more fleeting than others, are provided by three diverse areas of research: (a) number of others in a social dilemma, (b) helping persons versus groups, and (c) the self-serving bias.

\section{Number of Others in a Social Dilemma}

Social dilemmas involve situations of moderately noncorrespondent outcomes for self and other such that, if all participants maximize immediate selfinterest (e.g., listen but not donate to public radio), they collectively fare worse than if they maximize joint welfare (e.g., donate to public radio). Research has revealed an interesting tendency for people to behave more competitively (i.e., 
less prosocially) as the number of others in the dilemma increases (particularly in public-goods dilemmas), and a variety of explanations have been offered (Brewer \& Kramer, 1986). The implication from our motivational-primacy framework provides another explanation for the number-of-others effect.

What appears to be an effect of the number of others might be an effect of the nature of the others. If an increasing number of others promotes a psychological shift in the representation of the others from distinct persons to a group (S. L. Gaertner, Mann, Murrell, \& Dovidio, 1989), then, perhaps in an effort to simplify or reduce social information, any counter to individual-self interest provided by the relational self (through an interpersonal self-other connection) would diminish with the ensuing activation of the less potent collective self (through a group-based self-other connection). Consequently, if numbers could be held constant and people interacted with a single individual or a single group, then behavior would be more cooperative when interacting with the individual than with the group. Partial support for such a possibility is provided by the interindividual-intergroup discontinuity effect, which involves greater competition between interacting groups than between interacting individuals (Wildschut, Pinter, Vevea, Insko, \& Schopler, 2003). The only complication is that discontinuity research involves, for our purpose, a confounding of opponent (group vs. person) and actor (group vs. person). A direct test of the person-group implication requires a comparison of competition rates when a person interacts with a person versus with a group (for another approximation, see Wit \& Kerr, 2002, Experiment 2).

\section{Helping Persons Versus Groups}

Research indicates a stronger tendency to aid identified victims than nonidentified victims (Small \& Lowenstein, 2003). Consistent with the implication of a quieter ego when connecting with persons than with groups, this identifiedvictim effect is stronger when the victim is a person than when the victim comprises a group. Research by Kogut and Ritov (2005) illustrates the point. Participants in the unidentified condition learned of a sick 2-year-old or a group of eight sick 2-year-olds in need of expensive treatment for a deadly illness. Participants in the identified condition also viewed a photo of the patient or a group photo of the eight patients. In two such experiments, identification increased the money that participants were willing to contribute when the victim was a single person but had no effect when the victim comprised a group. A field study replicated this effect: Participants donated more money to the identified person than to the group.

Furthermore, the implication of an ego that is quieter in relations with persons than with groups is consistent with two competing pathways for enhanced helping through identification. As anticipated by the negative-state relief model (Cialdini et al., 1987), which suggests that helping is used egoistically to reduce personal distress, participants reported greater distress with an identified person than with a group (Kogut \& Ritov, 2005). Of course, the subsequent behavior of helping is ostensibly egoistic in the service of negativestate relief. However, the antecedent generation of a greater negative state 
by the suffering of an identified person than of a group is consistent with the quieter ego implication. Indeed, the pattern of distress tracks the finding that threat (represented in this instance by the victim's suffering) elicits a stronger response when directed to the relational self than to the collective self.

The distress ratings are open to another interpretation through the empathy-altruism hypothesis (Batson, 1991), which suggests that helping is altruistically motivated by concern for the identified victim. The ratings do not distinguish between personal distress and feeling distress for the victim, the latter of which correlate more strongly with the empathic antecedent of altruistic action (Batson, Early, \& Salvarani, 1997). As with personal distress, experiencing stronger distress for the identified person than for the group certainly follows the quieter ego implication (see chap. 15, this volume).

\section{Self-Serving Bias}

Reflecting the influence of the individual self, people engaged in tasks routinely seize credit for success and deny or displace blame for failure (Campbell \& Sedikides, 1999). Consistent with the implication of a quieter ego with social connections to a person, the self-serving bias on dyadic tasks is tempered by relationship closeness. Dyad members were less apt to seize egoistically credit for success and deny blame when their partner was a friend instead of a stranger, and such an effect was replicated when closeness was manipulated among strangers (Sedikides, Campbell, Reeder, \& Elliot, 1998, 2002). On group tasks, however, the self-serving bias is particularly pronounced (Miller \& Schlenker, 1985)-even on athletic teams, for which the self-group connection is conceivably strong (Mullen \& Riordan, 1988). As an apparent exception to the quieter ego implication, Schlenker and Miller (1977) reported reduced selfserving bias among members of high-cohesion groups than among members of low-cohesion groups. Two aspects of the research, however, bring into question whether the collective or relational self tempered the bias. Self-other attributions for responsibility involved ratings of individual group members instead of ratings of the group as a whole, which likely invoked the relational self instead of the collective self. Self-serving attributions are more robust when ratings focus on group-level performance (Mullen \& Riordan, 1988). Also, cohesion was manipulated through interpersonal similarity, which plausibly enhanced self-other connection at the interpersonal instead of the group level. Accordingly, Schlenker and Miller suggested that cohesion exerted its effect through "interpersonal bonds ... that mitigate against taking higher personal credit for success and low blame for failure" (p. 1039).

In any event, whether a reduced self-serving bias in a group task occurs through an interpersonal versus a group connection is awaiting controlled testing. As with the number of others in social dilemmas, however, our quieter ego implication offers a ready explanation for why the self-serving bias grows stronger with increasing group size (Mullen \& Riordan, 1988). With increasing size, perhaps the self-other connection shifts from an interpersonal to group bond (Prentice, Miller, \& Lightdale, 1994). 


\section{Are There Benefits of a Quieter Ego?}

Although the research we have discussed did not address directly the benefits of a quieter ego, an obvious speculation is that de-emphasizing the individual self in favor of the relational or collective self has the potential to promote social harmony. Indeed, as we suggested in the preceding section, the heightened emphasis of the relational self versus the collective self promoted a tendency to cooperate with and help other persons more so than other groups and reduced the tendency to seize credit for joint success and deny blame for joint failure on interpersonal more so than intragroup tasks. However, lurking behind the speculative benefit of quieting the motivational strivings of the individual self is a not-so-obvious potential danger. Imagine a total silencing of the individual self in favor of absolute collective-self striving. In such a state, persons would function in devotion to their group. Life within the group would be cooperative and harmonious; conflict over interests would be nonexistent (see chap. 3). However, what would life be like at the intersection of groups? With each member engaged in the betterment of the group, chaos and conflict between groups would perpetuate (see chap. 16). Of course, such conflict can readily occur with the strong strivings of the individual self. The motivational presence of the individual self, however, likely serves as an important check against collective action. Weighing in with "What about me?" drives people to speak up, protest, and sway others from the collective motion. A complete silencing of the individual self is ostensibly socially destructive, and the pursuit of such silencing potentially underestimates the individual-self's role in maintaining social harmony.

Perhaps optimal benefits for self and others ensue with a balance among the motivational striving of each self. The ability to self-define at the level of the individual, relationship, and group is unlikely a product of happenstance and instead an evolutionary consequence of the concurrent necessity for well-being and survival that is engendered by acting uniquely, connecting and uniting interpersonally, and existing in a broader collective (Sedikides \& Skowronski, 1997, 2000; Sedikides, Skowronski, \& Dunbar, 2006). The unmitigated striving of any form of self is likely detrimental, as would be the complete silencing of any self. The ideal psychological state to attend and promote the welfare of the individual, his or her interpersonal relations, and groups is likely achieved with equilibrium among the motivational strivings of the selves (see chap. 6 , this volume). An important area for future research is to develop an understanding of the dynamic interplay among the selves and the psychological processes that bring balance among selves.

\section{Conclusion}

On the basis of a motivational hierarchy among the three fundamental forms of self, we drew an implication for a quieter ego: Transcending the motivated strivings of the individual self occurs more readily for connections with persons than with groups. A foray into three relatively diverse areas of research sug- 
gested that the implication is certainly plausible. We offered the speculative warning, however, that a complete silencing of the individual self is not a productive means to a gentler world. Instead, a better solution might be obtained through a motivational balance among selves.

\section{References}

Batson, C. D. (1991). The altruism question: Toward a social psychological answer. Hillsdale, NJ: Erlbaum.

Batson, C. D., Early, S., \& Salvarani, G. (1997). Perspective taking: Imagining how another feels versus imagining how you would feel. Personality and Social Psychology Bulletin, 23, 751-758.

Baumeister, R. F., \& Leary, M. R. (1995). The need to belong: Desire for interpersonal attachments as a fundamental human motivation. Psychological Bulletin, 117, 497-529.

Bowlby, J. (1969). Attachment and loss: Vol. 1. Attachment. New York: Basic Books.

Brewer, M. B., \& Kramer, R. M. (1986). Choice behavior in social dilemmas: Effects of social identity, group size, and decision framing. Journal of Personality and Social Psychology, 50, $543-549$.

Campbell, W. K., \& Sedikides, C. (1999). Self-threat magnifies the self-serving bias: A metaanalytic integration. Review of General Psychology, 3, 23-43.

Caporael, L. (1997). The evolution of truly social cognition: The core configurations model. Personality and Social Psychology Review, 1, 276-298.

Cialdini, R. B., Schaller, M., Houlihan, D., Arps, K., Fultz, J., \& Beaman, A. L. (1987). Empathybased helping: Is it selflessly or selfishly motivated? Journal of Personality and Social Psychology, 52, 749-758.

Gaertner, L., Sedikides, C., \& Graetz, K. (1999). In search of self-definition: Motivational primacy of the individual self, motivational primacy of the collective self, or contextual primacy? Journal of Personality and Social Psychology, 76, 5-18.

Gaertner, L., Sedikides, C., Luke, M., \& Iuzzini, J. (2007). Motivational primacy in self-definition: Wherein lies the relational self? Unpublished manuscript, University of Tennessee.

Gaertner, L., Sedikides, C., Vevea, J. L., \& Iuzzini, J. (2002). The "I," the "we," and the "when": A meta-analysis of motivational primacy in self-definition. Journal of Personality and Social Psychology, 83, 574-591.

Gaertner, S. L., Mann, J. A., Murrell, A. J., \& Dovidio, J. F. (1989). Reduction of intergroup bias: The benefits of recategorization. Journal of Personality and Social Psychology, 57, 239-249.

Gollwitzer, P. M., \& Moskowitz, G. B. (1996). Goal effects on action and cognition. In E. T. Higgins \& W. Kruglanski (Eds.), Social psychology: Handbook of basic principles (pp. 361-399). New York: Guilford Press.

Kogut, T., \& Ritov, I. (2005). The "identified victim" effect: An identified group, or just a single individual? Journal of Behavioral Decision Making, 18, 157-167.

Miller, R. S., \& Schlenker, B. R. (1985). Egotism in group members: Public and private attributions of responsibility for group performance. Social Psychology Quarterly, 48, 85-89.

Mullen, B., \& Riordan, C. A. (1988). Self-serving attributions for performance in naturalistic settings: A meta-analytic review. Journal of Applied Social Psychology, 18, 3-22.

Prentice, D. A., Miller, D. T., \& Lightdale, J. R. (1994). Asymmetries in attachments to groups and to their members: Distinguishing between common-identity and common-bond groups. Personality and Social Psychology Builetin, 20, 484-493.

Schlenker, B. R., \& Miller, R. S. (1977). Group cohesiveness as a determinant of egocentric perceptions in cooperative groups. Human Relations, 30, 1039-1055.

Sedikides, C., Campbell, W. K., Reeder, G. D., \& Eiliot, A. J. (1998). The self-serving bias in relational context. Journal of Personality and Social Psychology, 74, 378-386.

Sedikides, C., Campbell, W. K., Reeder, G. D., \& Elliot, A. J. (2002). The self in relationships: Whether, how, and when close others put the self "in its place." In W. Stroebe \& M. Hewstone (Eds.), European review of social psychology (Vol. 12, pp. 237-265). Oxford, England: Wiley. 
Sedikides, C., \& Skowronski, J. J. (1997). The symbolic self in evolutionary context. Personality and Social Psychology Review, 1, 80-102.

Sedikides, C., \& Skowronski, J. J. (2000). On the evolutionary functions of the symbolic self: The emergence of self-evaluation motives. In A. Tesser, R. B. Felson, \& J. M. Suls (Eds.), Psychological perspectives on self and identity (pp. 91-117). Washington, DC: American Psychological Association.

Sedikides, C., Skowronski, J. J., \& Dunbar, R. I. M. (2006). When and why did the human self evolve? In M. Schaller, J. A. Simpson, \& D. T. Kenrick (Eds.), Evolution and social psychology: Frontiers in social psychology (pp. 55-80). New York: Psychology Press.

Small, D. A., \& Lowenstein, G. (2003). Helping a victim or helping the victim: Altruism and identifiability. Journal of Risk and Uncertainty, 26, 5-16.

Tice, D. M., \& Baumeister, R. F. (2001). The primacy of the interpersonal self. In C. Sedikides \& M. B. Brewer (Eds.), Individual self, relational self, and collective self (pp. 71-88). Philadelphia: Psychology Press.

Wildschut, T., Pinter, B., Vevea, J. L., Insko, C. A., \& Schopler, J. (2003). Beyond the group mind: A quantitative review of the interindividual-intergroup discontinuity effect. Psychological Bulletin, 129, 698-722.

Wit, A. P., \& Kerr, N. L. (2002). "Me versus just us versus us all": Categorization and cooperation in nested social dilemmas. Journal of Personality and Social Psychology, 83, 616-637. 